\title{
Effect of Prior Phacoemulsification Surgery in Trabeculectomy Surgery Outcomes
}

\author{
Sónia Torres-Costa $\mathbb{D}^{1}$, António Benevides Melo ${ }^{1,2}$, Sérgio Estrela-Silva $\mathbb{D}^{1,2}$, Fernando Falcão-Reis ${ }^{1,2}$, \\ João Barbosa-Breda (iD) \\ 'Department of Ophthalmology, Centro Hospitalar e Universitário São João, Porto, Portugal; ${ }^{2}$ Department of Surgery and Physiology, Faculty of \\ Medicine, University of Porto, Porto, Portugal; ${ }^{3}$ UnIC@RISE, Faculty of Medicine of the University of Porto, Porto, Portugal; ${ }^{4}$ Research Group \\ Ophthalmology, Department of Neurosciences, KU Leuven, Leuven, Belgium
}

Correspondence: Sónia Torres-Costa, Ophthalmology Department, Centro Hospitalar Universitário de São João, Alameda Professor Hernani Monteiro, Porto, 4200, Portugal, Tel +35I 225512 100, Fax +35I 225025 766, Email sonia.torres.costa@gmail.com

Purpose: To evaluate whether previous clear-cornea phacoemulsification surgery affects the surgical outcomes of trabeculectomy in open-angle glaucoma (OAG).

Methods: We performed a retrospective cohort study, which included 82 patients with OAG that underwent trabeculectomy between January 1, 2010, and December 31, 2017. The primary outcome was the probability of surgical failure. Failure was defined as IOP $>21$ $\mathrm{mmHg}$ or reduced $<20 \%$ from baseline, IOP $\leq 5 \mathrm{mmHg}$ in three consecutive visits, need for further glaucoma surgery, phthisis or loss of light perception vision due to glaucoma.

Results: Eighty-two eyes (58 phakic and 24 pseudophakic) were included. Phakic group patients were younger than those in the pseudophakic group, $65.8 \pm 11.7$ vs $76.2 \pm 7.9$ years $(\mathrm{p}<0.001)$. The most common type of glaucoma was primary OAG $[59 \%(\mathrm{n}=$ 34) phakic vs $63 \%(\mathrm{n}=15)$ pseudophakic], followed by exfoliative and pigmentary glaucomas. The mean preoperative IOP was not significantly different between groups nor was the number of preoperative hypotensive medications. The rate of surgical failure was not significantly different between groups at year $1[17 \%(\mathrm{n}=10)$ phakic vs $29 \%(\mathrm{n}=7)$ pseudophakic; $\mathrm{p}=0.361]$ nor at year $2[28 \%$ $(\mathrm{n}=16)$ phakic vs $46 \%(\mathrm{n}=11)$ pseudophakic; $\mathrm{p}=0.110]$. No significant differences were observed regarding the postoperative IOP or any secondary outcome measures at year 1 or 2 .

Conclusion: Previous clear-cornea phacoemulsification surgery does not lead to statistically significant differences in the rate of trabeculectomy failure. Despite not being significant, clinically relevant differences were observed between groups. Future studies with a larger sample and/or randomized are needed to clarify this association.

Keywords: trabeculectomy, phacoemulsification, surgical failure, intraocular pressure

\section{Introduction}

Trabeculectomy is the most common surgical procedure used to reduce intraocular pressure (IOP) in glaucoma patients in Portugal. ${ }^{1}$ Previous conjunctival incisions or intraocular surgical procedures could lead to a worse prognosis, because inflammation induces fibrosis in the subconjunctival space, which can adversely affect the surgical outcomes of trabeculectomy. ${ }^{2,3}$ Patients that had underwent extracapsular cataract extraction (which usually requires a conjunctival incision) had a lower surgical success after trabeculectomy. ${ }^{4-6}$ Starting in the 1990 s, clear-cornea phacoemulsification became the most common procedure for cataract extraction; it offers less ocular inflammation and no conjunctival scarring, which may be beneficial for the outcome of trabeculectomy. However, since the beginning of phacoemulsification, only four studies have been performed comparing trabeculectomy results between pseudophakic and phakic patients. ${ }^{7-10}$ Two studies (one retrospective ${ }^{7}$ and one prospective ${ }^{8}$ ) were written by the same authors and both studies included only Asian patients and the surgical approach for phacoemulsification included a conjunctival incision. In both studies, pseudophakia was identified as a prognostic factor for failure after trabeculectomy. 
Another retrospective study, in which phacoemulsification surgery was performed by clear-cornea approach, did not find significant differences between pseudophakic and phakic patients. ${ }^{9}$ Recently, a retrospective study performed in the United Kingdom compared the success of trabeculectomy surgery at 5 years. In this study, no significant differences were found between pseudophakic and phakic patients, but the surgical approach for phacoemulsification was not evident and the primary outcome measure was IOP. ${ }^{10}$

The purpose of the present study was to evaluate whether previous cataract extraction through clear-cornea phacoemulsification adversely affects the rate of surgical failure of trabeculectomy in eyes with open-angle glaucoma (OAG).

\section{Methods}

\section{Patient Selection}

This study was carried out in accordance with the Declaration of Helsinki and approved by the institutional review board of Centro Hospitalar Universitário de São João, Porto, Portugal.

Patient's informed consent regarding participation in this study was waived due to its retrospective nature, and no identifiable patient information has been divulged in the manuscript, assuring full patient data confidentiality. All patients signed a surgical informed consent prior to surgery.

This retrospective cohort study compares the outcome of trabeculectomy between phakic and pseudophakic eyes with OAG after clear-cornea phacoemulsification at 1 and 2 years of follow-up. The OAG are chronic, progressive optic neuropathies that have in common characteristic morphological changes at the optic nerve head and retinal nerve fiber layer as stated in the European Glaucoma Guidelines 5th edition.

All patients that underwent trabeculectomy between January 1, 2010, and December 31, 2017, at Centro Hospitalar Universitário de São João, were eligible. Given the retrospective nature of this study, indications for surgery were based on the surgeons' clinical practice patterns. Thus, patients were subjected to surgery if maximum-tolerated medically treated IOP was above target with a high probability of glaucoma progression, or if progressive glaucomatous damage was detected despite IOP reduction under maximal medical therapy. The eligible cases had to meet the following inclusion criteria:

1. Age 35 years or older at the time of glaucoma diagnosis.

2. Open angles on gonioscopy.

3. No history of conjunctival or intraocular surgery other than clear-cornea phacoemulsification performed, at least, 12 months before the trabeculectomy.

4. Only one eye was included per patient; in case both were eligible, the one with the longest follow up time was chosen.

5. Open-angle glaucoma cases, including primary OAG (POAG), exfoliative glaucoma (XFG) and pigmentary glaucoma (PG).

The exclusion criteria were:

1. Aphakia.

2. Other ocular pathologies than cataract or refractive error ( $<3 \mathrm{D}$ hyperopia or $<6 \mathrm{D}$ myopia).

3. Significant intraoperative or postoperative complications (other than posterior capsule rupture without need for anterior vitrectomy).

4. Any prior conjunctival surgery (including phacoemulsification through a sclerocorneal incision).

5. Trabeculectomy performed simultaneously with cataract surgery to the same eye. 


\section{Surgical Procedure}

All trabeculectomy procedures were performed by two experienced surgeons (A.M. and S.E.S) and all with a fornixbased surgical approach. A conjunctival incision was made along the limbus to create a fornix-based conjunctival flap at the superior conjunctiva. A 4-mm-wide per $3 \mathrm{~mm}$-deep rectangular scleral flap was then created. Mitomycin C (MMC) $(0.2 \mathrm{mg} / \mathrm{mL})$ or 5 -fluorouracil $(5-\mathrm{FU})(50 \mathrm{mg} / \mathrm{mL})$ was used through subconjunctival application of soaked sponges for 2 minutes for MMC and 5 minutes for 5-FU. Copious irrigation with balanced salt solution was performed to wash away residual MMC or 5-FU. A paracentesis tract was made in the peripheral temporal cornea, followed by the excision of a corneo-scleral block, after which peripheral iridectomy was performed. The scleral flap was closed using two sutures with 10-0 nylon, unless more were deemed necessary due to overfiltration. The conjunctival flap was sutured with a combination of single interrupted and continuous sutures with 10-0 nylon. In the early postoperative period, topical dexamethasone $1 \mathrm{mg} / \mathrm{mL}$, levofloxacin $5 \mathrm{mg} / \mathrm{mL}$ and flurbiprofen $0,3 \mathrm{mg} / \mathrm{mL}$ were administered 5 times daily and then tapered slowly over several weeks according to evolution. Laser suture lysis was performed during the early postoperative period when the IOP was higher than expected due to poor filtration (shallow/flat bleb with formed anterior chamber without leakage). All needling procedures were conducted in the operating room, under topical anesthesia, with the use of adjunctive $(5-\mathrm{FU})(50 \mathrm{mg} / \mathrm{mL})$.

\section{Data Collection}

The following demographic and clinical patient data were collected: sex, age of the patient at the time of surgery, type of glaucoma, preoperative IOP (measured in the 3 months preceding trabeculectomy), date of surgery, type of antimetabolite applied, postoperative IOP at 2 weeks and 1, 3, 6, 9, 12 and 24 months after surgery, preoperative best corrected visual acuity (BCVA) and then at 6,12 and 24 months after surgery, number of hypotensive medications preoperatively, 2 weeks after surgery and 1,3, 6, 9, 12 and 24 months after surgery, postoperative complications, number of needling procedures and other ocular surgeries performed after trabeculectomy. The IOP was measured in millimeters of mercury $(\mathrm{mmHg})$.

\section{Primary Outcome Measure}

The primary outcome was the probability of surgical failure. Failure was defined as IOP $>21 \mathrm{mmHg}$ or reduced $<20 \%$ from baseline, IOP $\leq 5 \mathrm{mmHg}$ in three consecutive visits, need for further glaucoma surgery, phthisis or loss of light perception vision due to glaucoma. High or low IOP values during the first 3 months after trabeculectomy were considered early postoperative IOP variation and/or the result of early postoperative complications rather than surgical failure. Needling and laser suture lysis were not considered as further glaucoma surgery and were therefore not considered as reasons for failure.

\section{Secondary Outcome Measures}

Secondary outcome measures included IOP and number of postoperative hypotensive medications at 2 weeks, 1, 3, 6, 9, 12 and 24 months, BCVA at 6,12 and 24 months, number of needling procedures, postoperative complications, and further glaucoma surgeries.

\section{Statistical Analysis}

Statistical analysis was performed using the SPSS statistical software (version 26.0 for Windows; SPSS Inc., Chicago, IL, USA) and STATA (version 13.1; StataCorp 4905 Lakeway Drive, College Station, Texas 77845, USA). Normality was assessed using a visual inspection of distribution plots and through Kolmogorov-Smirnov tests. Continuous variables were compared with parametric or non-parametric tests, according to the normality of data. Chi ${ }^{2}$ or Fisher's exact tests were performed for categorical variables.

Survival analysis was conducted in order to produce Kaplan-Meier curves and the Log rank test was conducted to compare the survival distributions of both groups.

A subgroup analysis was planned to ascertain the relevant outcomes after removing patients subjected to cataract surgery due to significant cataract development/progression. No patients were subjected to cataract surgery during the first 6 months after trabeculectomy. 
Multivariable logistic regression was performed to investigate the risk factors for trabeculectomy failure. The following variables were included as potential risk factors for surgical failure: pseudophakia, age, type of glaucoma, preoperative IOP, and type of antimetabolite. Statistical significance was considered when P was less than 0.05.

\section{Results}

\section{Baseline Characteristics}

In total, 82 eyes from 82 patients (58 phakic and 24 pseudophakic) were included (Table 1).

Table I Preoperative Characteristics of Eyes Submitted to Trabeculectomy in Phakic and Pseudophakic Patients

\begin{tabular}{|c|c|c|c|}
\hline & Phakic Group $(n=58)$ & Pseudophakic Group (n =24) & $P$ value \\
\hline Sex n (\%) male & $39(67.2)$ & $12(50.0)$ & $0.143^{*}$ \\
\hline Age y mean (SD) (range) & 65.8 (II.7) (37-84) & $76.2(7.9)(52-86)$ & $<0.001^{\dagger}$ \\
\hline Type of glaucoma $n(\%)$ & & & $0.880 *$ \\
\hline POAG & $34(59)$ & $15(63)$ & \\
\hline XFG & $20(35)$ & $8(33)$ & \\
\hline PG & $4(7)$ & I (4) & \\
\hline $\begin{array}{l}\text { Preoperative IOP } \mathbf{~ m m H g} \\
\text { mean (SD) (range) }\end{array}$ & $26.2(8.6)(14.0-56.0)$ & $24.5(9.2)(5.0-40.0)$ & $0.678^{\dagger}$ \\
\hline \multicolumn{4}{|c|}{ Preoperative hypotensive medications n (\%) } \\
\hline Mean (SD) & $3.14(0.93)$ & $3.26(0.92)$ & $0.601^{\ddagger}$ \\
\hline Median (Range) & $3.0(0-4)$ & $4.0(I-4)$ & $0.556^{\dagger}$ \\
\hline \multicolumn{4}{|l|}{ Number of drugs } \\
\hline PGA n (\%) & $36(62.1)$ & $16(66.7)$ & $0.694 *$ \\
\hline Betablocker n (\%) & $2(3.4)$ & $5(20.8)$ & $0.021^{* *}$ \\
\hline CAI n (\%) & II (19) & $6(25)$ & $0.559 * *$ \\
\hline Alfa-agonist n (\%) & $36(62.1)$ & II (45.8) & $0.176 *$ \\
\hline BB_PGA n (\%) & $19(32.8)$ & $4(16.7)$ & $0.140 *$ \\
\hline BB_CAI n (\%) & $28(48.3)$ & II (45.8) & $0.840 *$ \\
\hline BB_Aa n (\%) & $2(3.4)$ & $2(8.3)$ & $0.577^{* *}$ \\
\hline Aa_CAI n (\%) & $\mathrm{I}(\mathrm{l} .7)$ & $2(8.3)$ & $0.204^{* *}$ \\
\hline CAI oral n (\%) & $7(12.3)$ & I (4.3) & $0.427^{* *}$ \\
\hline $\begin{array}{l}\text { Preoperative BCVA logMAR } \\
\text { mean (SD) (Range) }\end{array}$ & $0.36(0.52)(0.0-2.0)$ & $0.44(0.57)(0.0-2.0)$ & $0.518^{\dagger}$ \\
\hline \multicolumn{4}{|c|}{ Intraoperative use of antimetabolite $\mathbf{n}(\%)$} \\
\hline 5-FU & $52(90)$ & $18(75)$ & \multirow[t]{2}{*}{$0.100 * *$} \\
\hline MMC & $6(10)$ & $6(25)$ & \\
\hline
\end{tabular}

Notes: *Chi square test, ${ }^{* *}$ Fisher's exact test, ${ }^{\dagger}$ Mann-Whitney $U$-test, ${ }^{\ddagger}$ Independent $t$-test.

Abbreviations: Aa_CAI, alfa2 adrenergic agonist plus carbonic anhydrase inhibitor; BB, betablocker; BB_Aa, betablocker plus alfa2 adrenergic agonist; BB_PGA, betablocker plus prostaglandin analog; BB_CAI, betablocker plus carbonic anhydrase inhibitor; BCVA, best-corrected visual acuity; CAI, Carbonic anhydrase inhibitors; IOP, intraocular pressure; logMAR, logarithm of the minimum angle of resolution; MMC, mitomycin C; $n$, number; PG, pigmentary glaucoma; PGA, prostaglandin analogs; POAG, primary open-angle glaucoma; SD, standard deviation; XFG, exfoliative glaucoma; y, years; 5-FU, 5-fluorouracil. 
All patients were Caucasian. Patients in the pseudophakic group were significantly older than those in the phakic group, $76.2 \pm 7.9$ vs $65.8 \pm 11.7$ years $(\mathrm{p}<0.001)$. The most common type of glaucoma in both groups was POAG, followed by XFG and then PG; no statistically significant differences were observed between groups regarding the type of glaucoma (Table 1). There were no statistically significant differences between groups regarding pre-operative IOP $(26.2 \pm 8.6 \mathrm{mmHg}$ phakic vs $24.5 \pm 9.2 \mathrm{mmHg}$ pseudophakic; $\mathrm{p}=0.678)$ or number of hypotensive medications $(3.14 \pm$ 0.93 phakic vs $3.26 \pm 0.92$ pseudophakic; $\mathrm{p}=0.601)$. Regarding the type of preoperative hypotensive medication, a statistically significant difference was observed in the use of topical betablocker $[3.4 \%(\mathrm{n}=2)$ phakic vs $20.8 \%(\mathrm{n}=5)$ pseudophakic; $\mathrm{p}=0.021]$.

\section{Primary Outcome Measure}

Surgical failure: There were no statistically significant differences between groups regarding the rate of surgical failure (with or without medication) at year $1[17 \%(\mathrm{n}=10)$ phakic vs $29 \%(\mathrm{n}=7)$ pseudophakic; $\mathrm{p}=0.361]$ or year $2[10 \%$ $(\mathrm{n}=6)$ phakic vs $17 \%(\mathrm{n}=4)$ pseudophakic; $\mathrm{p}=0.426]$. Cumulatively, after 2 years, the rate of failure was also not significantly different between groups $[28 \%(\mathrm{n}=16)$ phakic vs $46 \%(\mathrm{n}=11)$ pseudophakic; $\mathrm{p}=0.110]$. No surgical failure because of loss of light perception was observed.

Kaplan-Meier curves have been created for both groups (Figure 1) and the Log rank test shows no significant difference between them $(p=0.107)$.

\section{Secondary Outcome Measures}

IOP variation after surgery: After trabeculectomy, postoperative IOP levels were not statistically different between both groups at year 1 and 2 (Table 2, Figure 2).

Postoperative hypotensive medication: There were no significant differences in the mean number of postoperative hypotensive medication at year $1(0.55 \pm 0.94$ phakic vs $0.89 \pm 1.32$ pseudophakic; $\mathrm{p}=0.424$, Table 2$)$ or year $2(0.79 \pm$ 1.11 phakic vs $1.20 \pm 1.32$ pseudophakic; $\mathrm{p}=0.288$, Table 2 ).

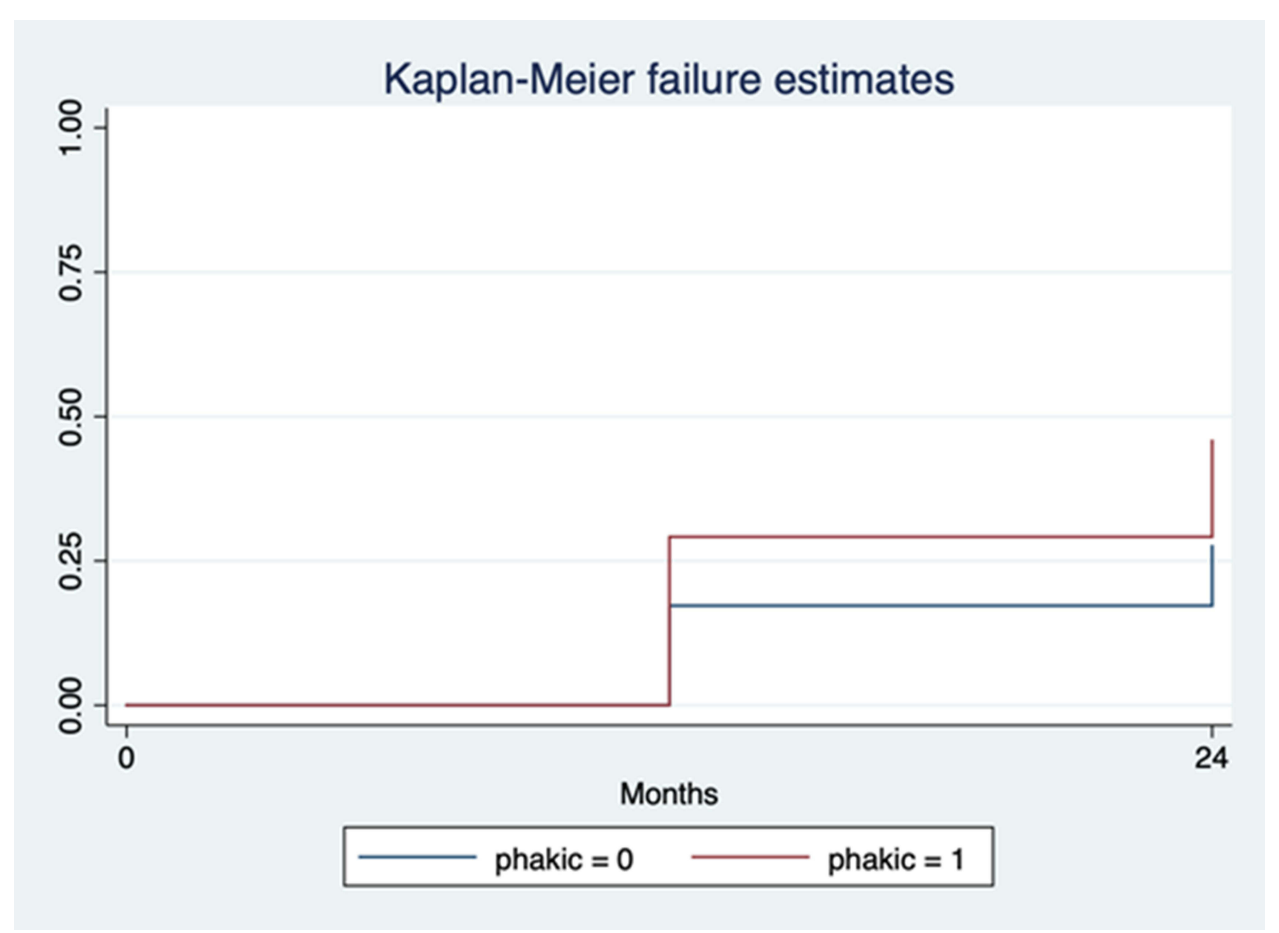

Figure I Survival analysis Kaplan-Meier curves for failure.

Notes: phakic $=0$ corresponds to the phakic group and phakic $=1$ to the pseudophakic group. Log rank test $p=0.107$. 
Table 2 Intraocular Pressure and the Number of Postoperative Hypotensive Medications Over Time After Trabeculectomy

\begin{tabular}{|c|c|c|c|c|c|c|}
\hline \multirow[t]{2}{*}{ Time } & \multicolumn{3}{|c|}{ IOP mmHg Mean (SD) (Range) } & \multicolumn{3}{|c|}{$\begin{array}{l}\text { No. of Postoperative Hypotensive Medications Mean (SD) } \\
\text { (Range) }\end{array}$} \\
\hline & Phakic Group & Pseudophakic Group & $P$ value & Phakic Group & Pseudophakic Group & $P$ value \\
\hline $2 w$ & 9.1 (5.1) (1.0-23.0) & $10.4(4.9)(2.0-20.0)$ & $0.273^{\ddagger}$ & 0 & 0 & NA \\
\hline I mo & $12.9(6.3)(3.0-40.0)$ & 14.3 (7.3) (5.0-30.0) & $0.427^{\dagger}$ & 0 & $0.17(0.56)(0.0-2.0)$ & $0.028^{\dagger}$ \\
\hline $3 \mathrm{mo}$ & I3.5 (4.3) (6.0-25.0) & $13.6(4.6)(4.0-21)$ & $0.918^{\dagger}$ & $0.21(0.62)(0.0-3.0)$ & $0.61(0.99)(0.0-3.0)$ & $0.049^{\dagger}$ \\
\hline $6 \mathrm{mo}$ & I $3.5(5.7)(4.0-36.0)$ & $13.0(4.6)(4.0-19.0)$ & $0.837^{\dagger}$ & $0.37(0.77)(0.0-3.0)$ & $0.68(1.00)(0.0-3.0)$ & $0.179^{\dagger}$ \\
\hline $9 \mathrm{mo}$ & I3.9 (5.9) (5.0-36.0) & $15.9(6.0)(5.0-29.0)$ & $0.168^{\dagger}$ & $0.44(0.91)(0.00-3.0)$ & $0.67(0.90)(0.0-2.0)$ & $0.268^{\dagger}$ \\
\hline $12 \mathrm{mo}$ & $14.0(5.5)(6.0-40.0)$ & $14.0(4.6)(8.0-26.0)$ & $0.918^{\dagger}$ & $0.55(0.94)(0.00-3.0)$ & $0.89(1.32)(0.0-4.0)$ & $0.424^{\dagger}$ \\
\hline $24 \mathrm{mo}$ & $14.4(5.1)(8.0-35.0)$ & I 4.4 (3.9) (7.0-20.0) & $0.649^{\dagger}$ & $0.79(1.11)(0.00-3.0)$ & $1.20(1.32)(0.0-4.0)$ & $0.288^{\dagger}$ \\
\hline
\end{tabular}

Notes: ${ }^{\dagger}$ Mann-Whitney U-test, ${ }^{\ddagger}$ Independent $t$-test.

Abbreviations: IOP, intraocular pressure; SD, standard deviation; w, weeks; mo, months; NA, not applicable.

Postoperative BCVA: There were no statistically significant differences between groups regarding postoperative BCVA (Table 3). Comparing preoperative with follow-up BCVA, the phakic group showed a significant reduction at year $1(0.36 \pm 0.52$ preop vs $0.64 \pm 0.87$ year $1 \operatorname{logMAR} ; \mathrm{p}=0.011)$, which remained at year $2(0.61 \pm 0.85 \operatorname{logMAR}, \mathrm{p}=$ 0.011). On the other hand, in the pseudophakic group, no significant differences were observed between preoperative BCVA $(0.44 \pm 0.57 \log \mathrm{MAR})$ with that at year $1(0.35 \pm 0.56 \operatorname{logMAR}, \mathrm{p}=1.000)$ and at year $2(0.29 \pm 0.50 \log \mathrm{MAR}$, $\mathrm{p}=0.755)$.

Surgical complications: There were no significant differences between groups regarding surgical complications (Table 4). Out of the 11 eyes with choroidal detachment, five were linked to wound leak. The remaining 6 were overfiltering blebs with early hypotony. All of these patients were managed conservatively, without surgical reintervention.

Number of needling procedures: In the first year of follow-up, needling was performed in $8(13.8 \%)$ eyes in the phakic group and in $4(16.7 \%)$ eyes in the pseudophakic group $(\mathrm{p}=0.740)$. In the second year of follow-up, no such procedures were performed.

Additional glaucoma surgery: To further reduce IOP during the follow-up period, 7 patients were subjected to a second glaucoma surgery. Of these, five patients were subjected to Ahmed glaucoma valve surgery and two repeated trabeculectomy. Four patients were phakic and three pseudophakic.

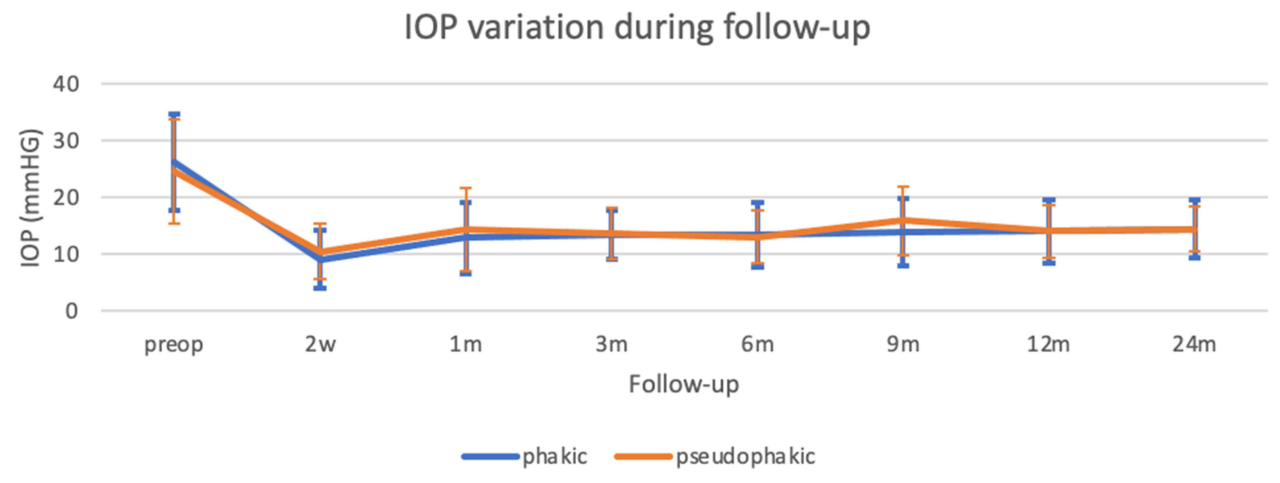

Figure 2 Intraocular pressure variation after trabeculectomy.

Notes: No statistically significant differences in IOP values between phakic and pseudophakic eyes were identified at any time point.

Abbreviations: IOP, intraocular pressure; w, weeks; m, months. 
Table 3 Postoperative BCVA Variation After Trabeculectomy

\begin{tabular}{|l|c|c|c|}
\hline BCVA LogMAR (SD) (Range) & Phakic Group & Pseudophakic Group & p value \\
\hline Preoperative & $0.36(0.52)(0.0-2.0)$ & $0.44(0.57)(0.0-2.0)$ & $0.518^{\dagger}$ \\
6 mo & $0.43(0.75)(0.0-3.0)$ & $0.41(0.60)(0.0-2.0)$ & $0.709^{\dagger}$ \\
12 mo & $0.64(0.87)(0.0-3.0)$ & $0.35(0.56)(0.0-2.0)$ & $0.344^{\dagger}$ \\
24 mo & $0.61(0.85)(0.0-3.0)$ & $0.29(0.50)(0.0-2.0)$ & $0.211^{\dagger}$ \\
\hline
\end{tabular}

Note: `Mann-Whitney U-test.

Abbreviations: BCVA, best-corrected visual acuity; logMAR, logarithm of the minimum angle of resolution; mo, months; SD, standard deviation.

Table 4 Postoperative Complications and Procedures in Pseudophakic and Phakic Eyes

\begin{tabular}{|c|c|c|c|}
\hline Postoperative Complication n (\%) & $\begin{array}{c}\text { Phakic Group } \\
\quad(n=58)\end{array}$ & $\begin{array}{l}\text { Pseudophakic Group } \\
\qquad(\mathrm{n}=24)\end{array}$ & $\mathrm{p}$ value \\
\hline Cataract progression requiring phacoemulsification surgery & $13(22)$ & NA & NA \\
\hline Choroidal detachment & $6(10)$ & $5(2 I)$ & $0.285^{* *}$ \\
\hline Flat anterior chamber & $8(14)$ & $2(8)$ & $0.716 * *$ \\
\hline Hyphema & $3(5)$ & I (4) & $1.000 * *$ \\
\hline Hemovitreous & 0 & 0 & NA \\
\hline Wound leak & $36(62)$ & II (46) & $0.176 *$ \\
\hline Bleb leak & $2(3)$ & $2(8)$ & $0.577^{* *}$ \\
\hline Hypotony maculopathy & $2(3)$ & 0 & $1.000 * *$ \\
\hline Blebitis & 0 & 0 & NA \\
\hline Endophthalmitis & $I(2)$ & 0 & $1.000 * *$ \\
\hline \multicolumn{4}{|l|}{ Needling } \\
\hline At I year & $8(14)$ & $4(17)$ & $0.740 * *$ \\
\hline At 2 years & 0 & 0 & NA \\
\hline Surgical bleb revision & 0 & 0 & NA \\
\hline Additional glaucoma surgery & $4(7)$ & $3(13)$ & $0.687 * *$ \\
\hline Trabeculectomy & $I(2)$ & I (4) & $0.502 * *$ \\
\hline Ahmed glaucoma valve & $3(5)$ & $2(8)$ & $0.627 * *$ \\
\hline
\end{tabular}

Notes: * Chi square test, ** Fisher's exact test.

Abbreviations: n, number; NA, not applicable.

\section{Subgroup Analysis}

Cataract progression requiring phacoemulsification surgery during the follow-up period occurred in 13 (22.4\%) patients. As such, a subgroup analysis excluding these patients was performed (45 phakic and 24 pseudophakic). After removing these patients, no statistically significant differences existed in any of the groups between preoperative BCVA and BCVA at year $1(0.35 \pm 0.53$ preop vs $0.59 \pm 0.92$ year $1 \operatorname{logMAR}, \mathrm{p}=0.140$ phakic; $0.44 \pm 0.57$ preop vs $0.35 \pm 0.56$ $\log$ MAR year $1, \mathrm{p}=1.000$ pseudophakic $)$ or at year $2(0.35 \pm 0.53$ preop vs $0.45 \pm 0.71$ year $2, \mathrm{p}=0.070$ phakic; $0.44 \pm$ 0.57 preop vs $0.29 \pm 0.50$ year $2, \mathrm{p}=0.755$ pseudophakic). There were no significant differences between groups regarding BCVA at baseline $(\mathrm{p}=0.447)$, at year $1(\mathrm{p}=0.949)$ or year $2(\mathrm{p}=0.607)$. Moreover, there were no statistically significant differences between groups regarding the rate of surgical failure (with or without medication) at year 1 [21.6\% 
$(\mathrm{n}=8)$ phakic vs $36.8 \%(\mathrm{n}=7)$ pseudophakic; $\mathrm{p}=0.223]$ or at year $2[20.6 \%(\mathrm{n}=7)$ phakic vs $37.5 \%(\mathrm{n}=6)$ pseudophakic; $\mathrm{p}=0.301]$. There were also no significant differences regarding postoperative IOP levels between groups at year $1(13.84 \pm 4.07 \mathrm{mmHg}$ phakic vs $14.08 \pm 4.89 \mathrm{mmHg}$ pseudophakic; $\mathrm{p}=0.908)$ or year $2(13.65 \pm 3.39 \mathrm{mmHg}$ phakic vs $13.69 \pm 3.73 \mathrm{mmHg}$ pseudophakic; $\mathrm{p}=0.806$ ). Furthermore, there were no significant differences in the mean number of postoperative hypotensive medications at year $1(0.45 \pm 0.93$ phakic vs $0.77 \pm 1.30$ pseudophakic; $p=0.129)$ or year $2(0.61 \pm 1.05$ phakic vs $1.15 \pm 1.41$ pseudophakic; $\mathrm{p}=0.179)$.

\section{Prognostic Factors for Failure of Trabeculectomy}

The following variables were assessed as potential risk factors for surgical failure: pseudophakia, age, type of glaucoma, preoperative IOP, and type of antimetabolite. In a multivariable logistic regression model, only preoperative IOP was significantly associated with the rate of failure, with $10 \%$ lower odds of failure for each $1 \mathrm{mmHg}$ increase in preoperative IOP (OR $0.89495 \%$ CI $(0.822-0.972) ; \mathrm{p}=0.003)$. The remaining results were pseudophakia (OR $2.81495 \%$ CI $(0.666-$ $11.884) ; \mathrm{p}=0.159)$, age (OR $0.98095 \%$ CI $(0.929-1.035) ; \mathrm{p}=0.472)$, type of glaucoma (OR $0.68995 \%$ CI $(0.373-$ $1.270) ; \mathrm{p}=0.233$ ), and type of antimetabolite (OR 0.415 95\% CI $(0.033-5.159) ; \mathrm{p}=0.494)$.

\section{Discussion}

In this retrospective study, we did not find significant differences in the rate of failure of trabeculectomy between phakic and pseudophakic eyes with OAG after clear-cornea phacoemulsification surgery. No significant differences existed between groups at baseline, except for a younger age in the phakic group $(76.2 \pm 7.9$ vs $65.8 \pm 11.7$ years, $\mathrm{p}<0.001)$.

Supawavej et al performed a retrospective study, including 78 patients (39 phakic eyes and 39 pseudophakic eyes) that underwent trabeculectomy with MMC after clear-cornea phacoemulsification, concluding that the probability of success of trabeculectomy for pseudophakic and phakic eyes was not different between the 2 groups. Regarding the ethnicity of patients included in this study, the great majority were white patients, but African-American, Hispanic and other non-mentioned ethnicities were also included in both phakic and pseudophakic groups. ${ }^{9}$

Mathew et al performed a European retrospective study to compare success rates at 5 years in three surgical groups. This study demonstrated that the overall success at 5 years was almost identical, $58 \%, 57 \%$ and $59 \%$ in groups 1 (trabeculectomy alone), 2 (trabeculectomy followed by cataract surgery within 2 years) and 3 (trabeculectomy performed on a pseudophakic eye), respectively $(\mathrm{p}>0.05)$. This study also showed that men may be at increased risk of failure. ${ }^{10}$ However, the surgical approach during phacoemulsification, namely clear-cornea or conjunctival approach, was not clarified. Moreover, direct comparisons would be unwise since Mathew et al presented long-term (5 years) results but not outcomes at 1 and 2 years (used by our study and other previous studies).

Takihara et al performed a prospective study, in Japan, among patients with OAG, including 39 phakic eyes and 25 pseudophakic eyes to compare the effect of previous phacoemulsification on trabeculectomy with MMC. Surgical failure was defined according to the following 3 IOP levels: $21 \mathrm{mmHg}$ or higher (criterion A), $18 \mathrm{mmHg}$ or higher (criterion B) and $15 \mathrm{mmHg}$ or higher (criterion $\mathrm{C}$ ). The probabilities of surgical failure at 1 year in the phakic vs pseudophakic group were $5 \%$ vs $27 \%$ for criterion A ( $p=0.04), 16 \%$ vs $41 \%$ for criterion B $(p=0.03)$, and $29 \%$ vs $50 \%$ for criterion C ( $p=$ 0.100). Pseudophakia was considered to be significantly associated with a worse surgical success and postoperative IOP in the pseudophakic group was significantly higher than in the phakic group at 6 and 9 months after trabeculectomy, but not at 12 months. $^{8}$ However, this study included eyes that had been subjected to phacoemulsification through a corneoscleral incision, which could have affected the mobility and scarring of the superior conjunctiva. In addition, the same research group also conducted a retrospective study, where the surgical prognosis of trabeculectomy was compared between 175 phakic eyes and 51 pseudophakic eyes among patients with OAG. Surgical failure was defined as an additional glaucoma surgery or 1 of the following 3 criteria: IOP of $21 \mathrm{mmHg}$ or greater (criterion A); IOP of 18 $\mathrm{mmHg}$ or greater (criterion B); and IOP of $15 \mathrm{mmHg}$ or greater (criterion C). At year 1, the probabilities of success in phakic eyes vs pseudophakic eyes were $97.8 \%$ vs $78.6 \%(\mathrm{p}<0.001)$ for criterion $\mathrm{A}, 92.9 \%$ vs $72.8 \%$ for criterion $\mathrm{B}(\mathrm{p}=$ $0.004)$, and $73.1 \%$ vs $53.1 \%$ for criterion $\mathrm{C}(\mathrm{p}=0.009)$. Pseudophakic eyes required significantly more medications at 6 and 12 months after trabeculectomy than phakic eyes. The aforementioned study also included eyes with previous 
phacoemulsification with incisions that involved the superior conjunctiva. ${ }^{7}$ Therefore, conclusions regarding the effect of pseudophakia on surgical success of trabeculectomy in OAG should be made cautiously.

Some possible explanations for trabeculectomy failure in pseudophakic eyes have been discussed in the previous literature. It has been demonstrated that intraocular surgery induces inflammation and breakdown of the blood-aqueous barrier. ${ }^{11}$ Monocyte chemoattractant protein 1 (MCP-1) induces the migration of leukocytes, possibly promoting subconjunctival and bleb fibrosis. A Japanese study demonstrated that MCP-1 levels were elevated in the aqueous humor of eyes subjected to phacoemulsification. ${ }^{12}$ Other study demonstrated that the interleukin- 8 and MCP-1 were significantly upregulated in pseudophakic OAG cases compared with phakic OAG. ${ }^{13}$ However, as this study only comprised Asian glaucoma patients, caution is necessary when generalizing results, since it is not yet known whether the same results would be obtained in a European Caucasian population. In fact, Jampel et al evaluated the probabilities of success and complications of trabeculectomy and demonstrated that the European-derived race had an increased rate of trabeculectomy success. ${ }^{14}$ Regarding the analysis of postoperative complications, in our study, choroidal detachment was more frequent in pseudophakic eyes $(n=5 ; 20.8 \%)$ than in the phakic eyes $(n=6 ; 10.3 \%)$, although no statistical significance was reached $(\mathrm{p}=0.285)$. Takihara et al also observed choroidal detachment more frequently in pseudophakic eyes when compared to phakic eyes [9 in $25(36 \%)$ pseudophakic vs 6 in $39(15 \%)$ phakic; $p=0.06]{ }^{8}$ Previously, the Collaborative Initial Glaucoma Treatment Study (CIGTS) Group reported that older patients have a higher probability of choroidal detachment after trabeculectomy ${ }^{15}$ In our study, pseudophakic patients were significantly older $(76.2 \pm 7.9$ years) than patients in the phakic group $(65.8 \pm 11.7$ years, $\mathrm{p}<0.001)$. Therefore, one possible explanation for the higher frequency of choroidal detachment in the pseudophakic group may have been associated with the fact that these patients were older.

Moreover, previous studies suggested that younger patients have a higher risk of trabeculectomy failure. ${ }^{16,17}$ It has been hypothesized that older patients may have less fibroblast activation and inflammatory cells than younger patients, contributing to a better outcome after trabeculectomy. ${ }^{3}$ In our study, pseudophakic patients were older than phakic patients. If older age would have in fact played a protective role, the absence of statistically significant differences in surgical outcomes could have been the result of this protective effect counterbalancing the negative effect of previous cataract surgery. Future studies should address this problem in which the success of trabeculectomy may be affected by age and ethnicity.

Cataract progression requiring phacoemulsification surgery occurred in 13 out of 58 (22.4\%) eyes. Other studies have also observed cataract progression after trabeculectomy. ${ }^{8,18,19}$ Deterioration of BCVA was observed in the phakic group with BCVA decreasing from $0.36 \pm 0.52 \log$ MAR to $0.61 \pm 0.85 \log$ MAR at 2 years. A subgroup analysis excluding eyes subjected to phacoemulsification during follow-up, showed that no significant differences existed in the phakic group between the preoperative BCVA and BCVA at year $1(\mathrm{p}=0.140)$ or at year $2(\mathrm{p}=0.070)$. This makes it likely that cataract progression was behind the significant decrease in BCVA. Cataract surgery during the follow-up period might have led to inflammation and to a higher trabeculectomy failure rate in this group than would be expected. ${ }^{20,21}$ Nonetheless, no differences in the rate of surgical failure were noted after excluding these patients.

One major limitation of the present study was the small sample size. As known, a small sample size decreases the statistical power of the study, reducing the chance of detecting a true effect. For instance, in our study, no statistically significant differences were observed in the rate of trabeculectomy surgical failure when comparing phakic and pseudophakic eyes with prior clear-cornea phacoemulsification. However, the relative number of eyes with failure at year 1 and 2 was superior in the pseudophakic group, which might be clinically relevant despite the absence of statistically significant differences. Another limitation was the retrospective design. A potential bias is the significant age difference, with pseudophakic patients being older. As previously explained, younger patients have a higher likelihood of failure, while older patients have a higher rate of complications, such as choroidal detachment. Moreover, we did not take into account the duration of prior topical hypotensive treatment. Chronic use of eye drops may induce ocular surface changes, as demonstrated by previous studies that identified an abnormally high production of interleukins and inflammatory markers, ${ }^{22,23}$ which may have a deleterious influence on glaucoma surgery outcomes. ${ }^{24}$ Furthermore, another limitation of our study is the heterogeneity regarding the use of adjuvant antimetabolite [5-FU use in $52(90 \%)$ eyes in the phakic group and 18 eyes (75\%) in the pseudophakic group]. Recent evidence suggests that MMC is more 
effective in reducing IOP and trabeculectomy surgical failure. ${ }^{25,26}$ As such, in our department, we currently almost only use MMC. Nonetheless, our multivariable regression analysis did not show this heterogeneity to be a significant predictor of failure. Finally, in our subgroup analysis, we only excluded the 13 eyes that were subjected to phacoemulsification surgery, but other eyes might also have had cataract progression with less impact on quality of life.

In conclusion, among patients with OAG, no statistically significant differences were observed in the rate of surgical failure of trabeculectomy when comparing phakic and pseudophakic eyes with prior clear-cornea phacoemulsification. Nonetheless, the relative number of eyes with failure at year 1 and 2 was superior in the pseudophakic group, which might be clinically relevant despite the absence of statistically significant differences. Therefore, further studies should be conducted with a larger sample, and ideally with randomization, to elucidate this association.

\section{Abbreviations}

BCVA, best-corrected visual acuity; D, diopter; IOP, intraocular pressure; MMC, mitomycin C; OAG, open-angle glaucoma; OR, odds ratio; PG, pigmentary glaucoma; POAG, primary open angle glaucoma; XFG, exfoliative glaucoma; 5-FU - 5-fluorouracil.

\section{Funding}

There is no funding to report.

\section{Disclosure}

Meeting Presentation: 10th International Congress on Glaucoma Surgery (ICGS), London, 6-8 February 2020. Portuguese Ophthalmology Society Meeting, December 2021.

The authors report no conflicts of interest for this work.

\section{References}

1. Barbosa-Breda J, Goncalves-Pinho M, Santos JV, et al. Trends in glaucoma surgical procedures in Portugal: a 16-year nationwide study (20002015). J Glaucoma. 2018;27(8):682-686. doi:10.1097/IJG.0000000000001011

2. Broadway DC, Chang LP. Trabeculectomy, risk factors for failure and the preoperative state of the conjunctiva. J Glaucoma. 2001;10(3):237-249. doi:10.1097/00061198-200106000-00017

3. Law SK, Shih K, Tran DH, Coleman AL, Caprioli J. Long-term outcomes of repeat vs initial trabeculectomy in open-angle glaucoma. Am J Ophthalmol. 2009;148(5):685-695.e681. doi:10.1016/j.ajo.2009.05.032

4. Broadway DC, Grierson I, Hitchings RA. Local effects of previous conjunctival incisional surgery and the subsequent outcome of filtration surgery. Am J Ophthalmol. 1998;125(6):805-818. doi:10.1016/S0002-9394(98)00045-2

5. Gross RL, Feldman RM, Spaeth GL, et al. Surgical therapy of chronic glaucoma in aphakia and pseudophakia. Ophthalmology. 1988;95 (9):1195-1201. doi:10.1016/S0161-6420(88)33027-7

6. Bellows AR, Johnstone MA. Surgical management of chronic glaucoma in aphakia. Ophthalmology. 1983;90(7):807-813. doi:10.1016/S01616420(83)34483-3

7. Takihara $\mathrm{Y}$, Inatani $\mathrm{M}$, Seto $\mathrm{T}$, et al. Trabeculectomy with mitomycin for open-angle glaucoma in phakic vs pseudophakic eyes after phacoemulsification. Arch Ophthalmol. 2011;129(2):152-157. doi:10.1001/archophthalmol.2010.348

8. Takihara Y, Inatani M, Ogata-Iwao M, et al. Trabeculectomy for open-angle glaucoma in phakic eyes vs in pseudophakic eyes after phacoemulsification: a prospective clinical cohort study. JAMA Ophthalmol. 2014;132(1):69-76. doi:10.1001/jamaophthalmol.2013.5605

9. Supawavej C, Nouri-Mahdavi K, Law SK, Caprioli J. Comparison of results of initial trabeculectomy with mitomycin C after prior clear-corneal phacoemulsification to outcomes in phakic eyes. J Glaucoma. 2013;22(1):52-59. doi:10.1097/IJG.0b013e31821e8607

10. Mathew RG, Parvizi S, Murdoch IE. Success of trabeculectomy surgery in relation to cataract surgery: 5-year outcomes. Br J Ophthalmol. 2019;103(10):1395-1400. doi:10.1136/bjophthalmol-2018-312972

11. Joseph JP, Grierson I, Hitchings RA. Chemotactic activity of aqueous humor. A cause of failure of trabeculectomies? Arch Ophthalmol. 1989;107 (1):69-74. doi:10.1001/archopht.1989.01070010071030

12. Kawai M, Inoue T, Inatani M, et al. Elevated levels of monocyte chemoattractant protein-1 in the aqueous humor after phacoemulsification. Invest Ophthalmol Vis Sci. 2012;53(13):7951-7960. doi:10.1167/iovs.12-10231

13. Inoue T, Kawaji T, Inatani M, Kameda T, Yoshimura N, Tanihara H. Simultaneous increases in multiple proinflammatory cytokines in the aqueous humor in pseudophakic glaucomatous eyes. J Cataract Refract Surg. 2012;38(8):1389-1397. doi:10.1016/j.jcrs.2012.04.028

14. Jampel HD, Solus JF, Tracey PA, et al. Outcomes and bleb-related complications of trabeculectomy. Ophthalmology. 2012;119(4):712-722. doi:10.1016/j.ophtha.2011.09.049

15. Jampel HD, Musch DC, Gillespie BW, Lichter PR, Wright MM, Guire KE. Perioperative complications of trabeculectomy in the collaborative initial glaucoma treatment study (CIGTS). Am J Ophthalmol. 2005;140(1):16-22. doi:10.1016/j.ajo.2005.02.013

16. Landers J, Martin K, Sarkies N, Bourne R, Watson P. A twenty-year follow-up study of trabeculectomy: risk factors and outcomes. Ophthalmology. 2012;119(4):694-702. doi:10.1016/j.ophtha.2011.09.043 
17. The Advanced Glaucoma Intervention Study (AGIS). 11. Risk factors for failure of trabeculectomy and argon laser trabeculoplasty. Am J Ophthalmol. 2002;134(4):481-498. doi:10.1016/S0002-9394(02)01658-6

18. The Advanced Glaucoma Intervention Study. 8. Risk of cataract formation after trabeculectomy. Arch Ophthalmol. $2001 ; 119(12): 1771-1779$. doi:10.1001/archopht.119.12.1771

19. Musch DC, Gillespie BW, Niziol LM, et al. Cataract extraction in the collaborative initial glaucoma treatment study: incidence, risk factors, and the effect of cataract progression and extraction on clinical and quality-of-life outcomes. Arch Ophthalmol. 2006;124(12):1694-1700. doi:10.1001/ archopht.124.12.1694

20. Dada T, Bhartiya S, Begum Baig N. Cataract surgery in eyes with previous glaucoma surgery: pearls and pitfalls. J Curr Glaucoma Pract. 2013;7 (3):99-105. doi:10.5005/jp-journals-10008-1145

21. Rebolleda G, Muñoz-Negrete FJ. Phacoemulsification in eyes with functioning filtering blebs: a prospective study. Ophthalmology. 2002;109 (12):2248-2255. doi:10.1016/S0161-6420(02)01246-0

22. Baudouin C, Liang H, Hamard P, et al. The ocular surface of glaucoma patients treated over the long term expresses inflammatory markers related to both T-helper 1 and T-helper 2 pathways. Ophthalmology. 2008;115(1):109-115. doi:10.1016/j.ophtha.2007.01.036

23. Baudouin C, Hamard P, Liang H, Creuzot-Garcher C, Bensoussan L, Brignole F. Conjunctival epithelial cell expression of interleukins and inflammatory markers in glaucoma patients treated over the long term. Ophthalmology. 2004;111(12):2186-2192. doi:10.1016/j. ophtha.2004.06.023

24. Broadway DC, Grierson I, O’Brien C, Hitchings RA. Adverse effects of topical antiglaucoma medication. II. The outcome of filtration surgery. Arch Ophthalmol. 1994;112(11):1446-1454. doi:10.1001/archopht.1994.01090230060021

25. Pimentel E, Schmidt J. Is mitomycin better than 5-fluorouracil as antimetabolite in trabeculectomy for glaucoma? Medwave. 2018;18(1):e7137. doi:10.5867/medwave.2018.01.7138

26. Cabourne E, Clarke JC, Schlottmann PG, Evans JR. Mitomycin C versus 5-Fluorouracil for wound healing in glaucoma surgery. Cochrane Database Syst Rev. 2015;2015(11):Cd006259.

Clinical Ophthalmology

Dovepress

\section{Publish your work in this journal}

Clinical Ophthalmology is an international, peer-reviewed journal covering all subspecialties within ophthalmology. Key topics include: Optometry; Visual science; Pharmacology and drug therapy in eye diseases; Basic Sciences; Primary and Secondary eye care; Patient Safety and Quality of Care Improvements. This journal is indexed on PubMed Central and CAS, and is the official journal of The Society of Clinical Ophthalmology (SCO). The manuscript management system is completely online and includes a very quick and fair peer-review system, which is all easy to use. Visit http://www. dovepress.com/testimonials.php to read real quotes from published authors.

Submit your manuscript here: https://www.dovepress.com/clinical-ophthalmology-journal 